\title{
An assessment of census techniques, habitat use and threats to Swamp Francolin Francolinus gularis in Koshi Tappu Wildlife Reserve, Nepal
}

\author{
BHAGAWAN RAJ DAHAL, PHILIP J. K. McGOWAN and \\ STEPHEN J. BROWNE
}

\begin{abstract}
Summary
Swamp Francolin Francolinus gularis is endemic to the Indian sub-continent, being found in India, Nepal and Bangladesh. It is threatened with extinction and is listed as 'Vulnerable', mainly as a result of habitat degradation and loss. This study investigated the distribution, habitat use, threats and most appropriate method for surveying the species at Koshi Tappu Wildlife Reserve in southeastern Nepal from February to July 2004. The most appropriate method, which recorded the highest number of birds (without double-counting), was identified as point counts undertaken early in the morning during the breeding season. The abundance estimate for the species was $15.5 \pm 2.50$ birds $\mathrm{km}^{-2}$. Habitat use, as compared with availability, differed significantly between seasons, with Woodland-Grassland and Wet Grassland preferred in the breeding season and summer. Dry Grassland and Woodland were preferred during the monsoon months. On average, 40.4 ( \pm 15.6) people were recorded in the study area each day and there was a general trend for the number of birds to decrease with increasing numbers of people. Each day an average of 31.6 ( \pm 16.7) livestock was recorded in the study area and more than 120 were regularly present throughout the eastern section, although there was no significant relationship between number of cattle and Swamp Francolin. We conclude that as long as the degree and distribution of anthropogenic pressures does not increase, the Swamp Francolin should survive at Koshi Tappu Wildlife Reserve. However, as the species is reliant on different habitats in different seasons, deterioration in the quality or extent of either of these could have a serious impact on the species.
\end{abstract}

\section{Introduction}

Swamp Francolin Francolinus gularis is a globally threatened species (BirdLife International 2004, Fuller et al. 2000, IUCN 2006) that is restricted to the low-lying terai grasslands of India, Nepal and Bangladesh (Ali and Ripley 1987, Grimmett et al. 2000, McGowan et al. 1995, Sarkar and Sarkar 2001). It is considered to be 'Vulnerable' to extinction and concern over its status was first raised in the early 1990s when brief surveys were carried out principally in Uttar Pradesh in northern India (Kaul and Kalsi 1990, Javed and Rahmani 1991). These surveys highlighted that, as the species inhabited fragmented patches of tall wet grassland throughout the terai, it was susceptible to changes in land-use that altered the water level, such as drainage for agriculture. Consequently it was increasingly confined to small and isolated areas (see McGowan et al. 1995).

Koshi Tappu Wildlife Reserve is one of the global strongholds for Swamp Francolin and may hold the highest concentration of the species within any protected area. Even so, within this reserve there is habitat degradation and substantial use of the grassland and wetland resources 
and the species is under threat. Habitats within the reserve are subject to intense pressure from grazing by domestic livestock, cutting, burning, hunting, fishing, water management schemes, and conversion of land for agriculture (Kalsi et al. 2001).

This study was implemented to: assess the most appropriate field protocol, time and season for determining abundance; estimate the density of Swamp Francolin at Koshi Tappu Wildlife Reserve; determine key habitats in different seasons; assess human impacts; and provide management recommendations to aid the conservation of the species within the reserve.

\section{Methods}

Study site

The study was conducted in the eastern sector of Koshi Tappu Wildlife Reserve (Koshi Tappu) $\left(85^{\circ} 56^{\prime}-87^{\circ} 0^{\prime}\right.$ E, $26^{\circ} 56^{\prime}-26^{\circ} 40^{\prime} N$ ) (Figure 1 ), which lies in the floodplain of the Sapta Koshi River in southeastern lowland Nepal. The reserve was officially established in 1976 and extended in 1980 to cover $175 \mathrm{~km}^{2}$ in Saptari, Udayapur and Sunsari districts. The habitat within Koshi Tappu is broadly classified as forest $(5.4 \%)$, grassland $(17.1 \%)$, swamp $(18.1 \%)$, river $(52.4 \%)$ and agricultural land $(7.0 \%)$. The natural vegetation of the reserve is mainly characterised by mixed deciduous riverine forest, Dalbergia sissoo/Acacia catechu mixed forest, grasslands and marshy vegetation. An invasive vine Mikania micrantha covers some of the vegetation on the northern end of the eastern embankment.

Essentially, the reserve is bounded by two parallel embankments, one to the west and one to the east of the Sapta Koshi River. The river meanders between the two embankments, with its course and size varying greatly with season and year. During the monsoon the river floods much of the land up to the embankments and after the waters recede the course of the river is often different from that prior to the rains. In order to prevent erosion of the embankments, bunds (banks of soil and stone) extend perpendicularly from the embankments towards the river. The bunds are situated about every $150-200 \mathrm{~m}$ and the land between them supports the grassland and trees that comprise the area where Swamp Francolin occur.

The study was carried out along an $11 \mathrm{~km}$ stretch of the embankment that formed the eastern boundary of the reserve. The embankment has villages to the east (outside the reserve) and a narrow strip of land to the west that varies in width between about $50 \mathrm{~m}$ and $300 \mathrm{~m}$ with bunds every $150-200 \mathrm{~m}$.

\section{Survey design}

In order to gather information to identify the most appropriate protocol, season, and time of day to survey Swamp Francolin, we conducted line transects and point counts in different seasons and at different times of the day. The survey period was categorised into three periods, breeding (February-March), summer (April-May) and monsoon (June-July). The morning survey period was also categorised as early (o5h45-07h15, o5h30-07hoo and o5h15-06h45) and late (o7h2oo8h5o, o7ho5-08h35 and o6h50-08h2o) for the breeding, summer and monsoon seasons respectively. Fieldwork was carried out from February to July 2004.

\section{Line transects}

Six line transects of $1.5 \mathrm{~km}$ were established in a north-south direction along the top of the eastern embankment of the reserve. Birds were only present on the western side of the embankment, as human settlements made the area to the east unsuitable. However, a transect through the middle of the area to the west of the embankment would have been logistically difficult and in any case calling birds were easily recorded to the edge of the river, which formed the boundary of the study area. Each of the six transects was surveyed on foot at a constant pace 


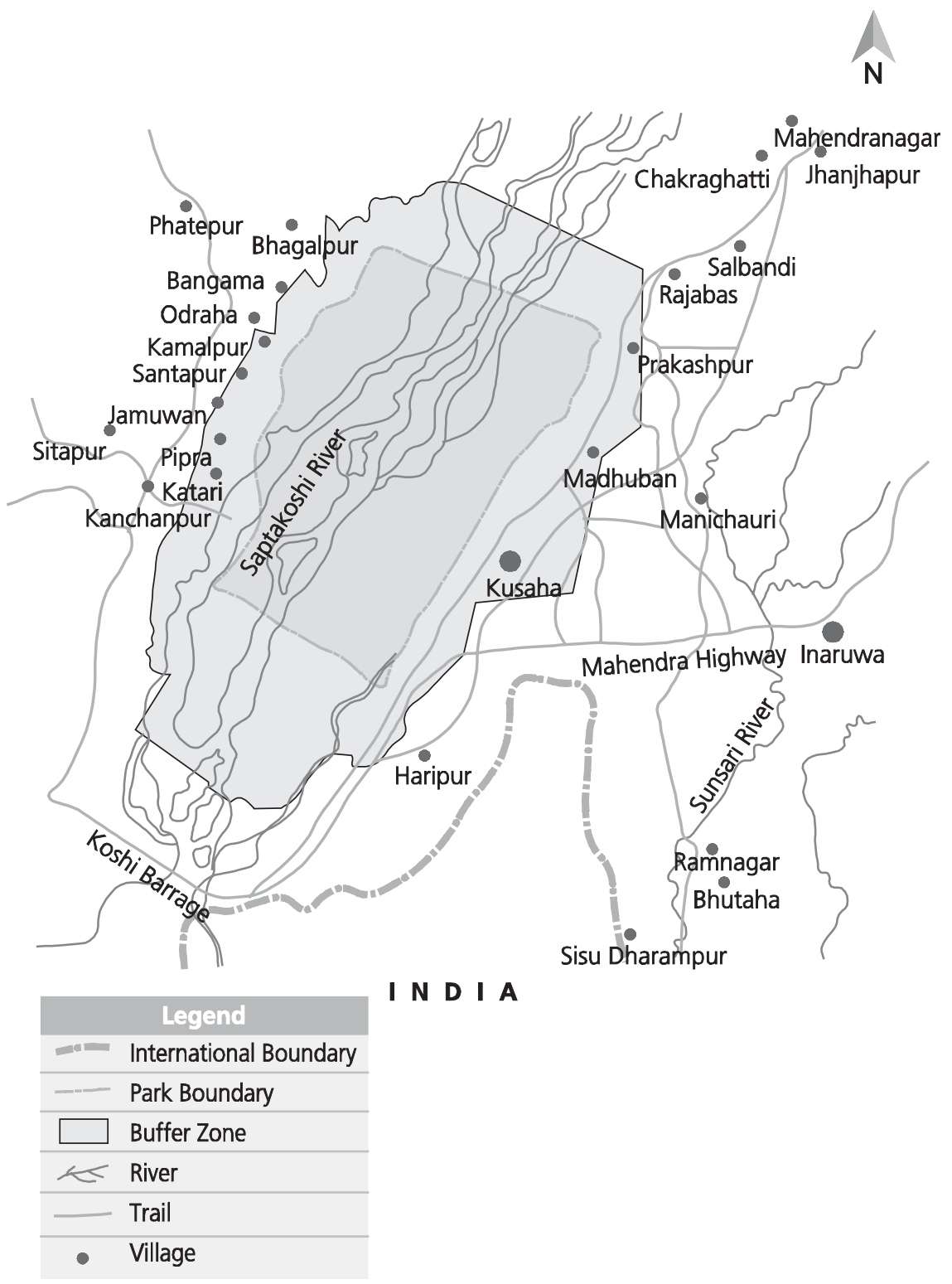

Figure 1. Map of Koshi Tappu Wildlife Reserve, Nepal showing villages and point count survey locations. Adapted from Baral and Inskipp (2005).

to ensure that each transect was covered in about 90 minutes. The transects were surveyed three times each month, so that each transect was surveyed six times per season and 18 times per year. In total, 108 transects were surveyed per year representing $162 \mathrm{~km}$ of surveys. When each bird was heard calling, its distance and direction from the observer were estimated using landscape or vegetation features as reference points for distance measurements, and details of habitat use were recorded (see later). The direction and distance of each calling bird from the observer was used to ensure that calling birds were not double-counted. One transect was surveyed per day, initially in 
one direction, constituting the early survey, and then after a short time, in the other direction to form the late survey.

\section{Point counts}

Using the protocol developed by McGowan et al. (1996) to survey Swamp Francolin, 12 point count survey points were established, this being the number required to provide sufficient cover of the survey area. These were situated randomly, but at least $700 \mathrm{~m}$ from the next nearest point, on top of the bunds that projected perpendicularly from the embankment, so that there were two points in each of the $1.5-\mathrm{km}$ line transects. The two points within each transect were surveyed on the same day, each for 90 minutes, with the 90 minutes at the first point representing the early count and the 90 minutes at the second the late count. Each point was surveyed only during the early or late morning throughout the whole study and three times per month, six times per season in total. When a bird was heard calling, the distance and direction from the observer were estimated, its activity was recorded and details of habitat use were recorded (see later). The direction and distance of each calling bird from the observer was used to ensure that calling birds were not double-counted.

\section{Habitat and disturbance variables}

Detailed habitat information was collected by randomly placing ten $10 \mathrm{x} 10 \mathrm{~m}$ quadrats within the area of the reserve to the west of, and adjacent to, each of the six $1.5-\mathrm{km}$ transect lengths, giving a total of 60 habitat sampling points. They were established by dividing each $1.5-\mathrm{km}$ transect into two $0.75-\mathrm{km}$ sections, then firstly by walking for two minutes into the grassland perpendicular to the embankment, where the first was established, then for two minutes due south for the second, two minutes east for the third, etc. The different topography and ease of access through the vegetation meant that the quadrats were not placed in a regular square. This process was repeated for each $0.75-\mathrm{km}$ section. When a bird was heard calling its approximate location was estimated and a broad description of vegetation (e.g. woodland, grassland, mixed, etc) recorded, together with approximate plant cover and dominant plant species. The plants were either identified in situ with assistance from local people and wildlife technicians from the Biodiversity Conservation Centre at the Royal Chitwan National Park or a sample was collected for later identification at the Godawari Herbarium Centre, Kathmandu; as a result no species were unidentified.

Additionally, during each line transect and point count survey, the number of people and livestock (principally cattle) present within $150 \mathrm{~m}$ of each transect or point count location and to the west of the embankment, were counted. Any additional people or livestock that entered the survey area during the course of the survey were also noted.

\section{Statistical analysis}

To establish the best surveying protocol in relation to method, time of day and season, an Analysis of Variance (ANOVA) was used to test for differences in the number of Swamp Francolin heard calling using the two protocols at different times of day and in the different seasons. The ANOVA used the mean number of birds recorded each season $(\log (\mathrm{x}+\mathrm{I})$ transformed) at each point count location or line transect section, as the dependent variable and the protocol, time of day and season as the independent variable. Having established which protocol and time of year and day collected the greatest number of Swamp Francolin records, the data derived were then used for further analysis.

The probability of detecting an individual francolin as a function of its distance from the observer was modelled using the programme DISTANCE 4.I (Buckland et al. 2001). We assumed that all key assumptions (e.g. objects on the point are detected with certainty, objects are detected 
at their initial location and measurements are exact) were fulfilled as a pre-requisite to using the procedure. A number of checks were employed to ensure that double-counting did not occur, for example the distance and direction of each call and the pattern of calling were noted and carefully mapped and any repeat calls that may have come from the same individual were only recorded once. Sufficient field observations $(n=76)$ were collected for the purpose of abundance estimation, following the recommendation of Buckland et al. (2001) to have a minimum of 6o-80 observations. We modelled the detection function of the species as uniform key with cosine, halfnormal with cosine and half-normal with polynomial adjustments models. Data were truncated and grouped. Model fit was assessed with chi-squares model-fit statistics. In addition to the abundance estimation the detection probability and encounter rate were also estimated.

The habitat information was classified into four broad habitat categories based on the dominant plant species and amount of water present. The four categories were Woodland, where greater than $50 \%$ of land cover was trees; Woodland-Grassland mixture, where less than $50 \%$ of land cover was trees and these areas were interspersed with grasses; Wet Grassland, where grasses dominated, no trees were present and the area contained water; and Dry Grassland, where grasses dominated, no trees were present and the area contained no water (Table 1). Compositional analysis (Aitchison 1986) was used to compare habitat availability and use on the study site in relation to season (Aebischer et al. 1993). A measure of habitat use was derived by calculating the proportions of all Swamp Francolin records that were present within each of the four habitat categories, at each point count survey and in each season. Most bird records $(n=126)$ were collected using point counts undertaken in the early morning so only observations from that method and period were used. The proportion of quadrats that were assigned to each of the four habitat categories around each count point survey represented habitat availability. Additionally a ranking matrix of habitat use relative to availability was produced (Aebischer et al. 1993).

To assess whether the number of people and livestock varied in relation to season and time of day an ANOVA was used. The mean number of people or livestock recorded in each transect section or point count location was used separately as the dependent variable with season and time of day as the factors, data were $\log (x+1)$ transformed before analysis. To investigate the relationship between the number of birds and the number of people and livestock recorded on each count in relation to season, an Analysis of Covariance (ANCOVA) was used on data collected by the point count method in the early morning. Data collected during all three early morning counts within each season were used, with each point count representing a single observation.

All interactions were included in the models and if not significant were removed. Means and their associated standard errors (SE) are given. SYSTAT to was used for the analysis.

Table 1 . Habitat categorises used in the analysis. The classification is based on the dominant vegetation type.

\begin{tabular}{ll}
\hline Category & Dominant plant species \\
\hline Woodland & Dalbergia sisoo-Acacia catechu dominated in association with \\
& Zizyphus mauritiana, Trewia nudiflora, Bombex ceiba, \\
& Litsea monopatela and predominantly with Clerodendrum \\
& viscosum, Zizyphus mauritiana and Eucalyptus spp. \\
& Dalbergia sisoo-Acacia catechu in association with \\
Woodland-Grassland mix & Imperata cylindrical, Saccharum spontaneum, Phragmites karka \\
& and Mimosa pudica. Also containing Bombex cieia, Cyperus sp. \\
& and mix of Cynodon dactylon, Polygonum sp., Ludigia hyssopifolia, \\
& Cassia occidentali and Callicarpa macrophylla \\
& Dominated by Saccharum spontaneum, Phragmites karka, Saccharum \\
Wet Grassland & arundinaceum, Typha angustifolia, Typha elephantine and Oryza sp. \\
& with no associated shrub and tree species. \\
Dry Grassland & Imperata cylindrica and Cynodon dactylon dominated grassland \\
& with mixed ground vegetation and no associated shrub and tree species \\
\hline
\end{tabular}




\section{Results}

\section{Sampling protocol}

The number of calling birds recorded varied significantly with protocol $\left(F_{1,67}=14.22, P<0.001\right)$, season $\left(F_{2,67}=57.17, P<0.001\right)$ and time of day $\left(F_{1,67}=6.25, P=0.015\right)$. On average, $30 \%$ more birds were recorded each season using point counts compared with line transects, $40 \%$ more early in the morning compared with later, and in total twice as many during the breeding season than in the summer, which in turn recorded twice as many than during the monsoon.

\section{Abundance estimates}

Swamp Francolin abundance was estimated from the data collected during the early morning point count during the breeding period. The detection model, uniform key with simple polynomial adjustment, estimated abundance of Swamp Francolin as $15.5 \pm 2.50$ birds $^{-2}$ where the effective detection radius (EDR) and probability of observing an object in the defined area $(P)$ were $139 \mathrm{~m}$ and 0.323 respectively.

The other detection models that we explored, half-normal with polynomial adjustments and half-normal with cosine adjustments, produced similar abundance estimations of $17.7 \pm 2.92$ birds $\mathrm{km}^{-2}, \mathrm{EDR}=159 \mathrm{~m}, P=0.281$. However the former model was chosen as it provided an estimate that was relatively precise. Model fit was judged with the $\chi^{2}$ goodness of fit test based on grouping the data.

\section{Habitat use}

The habitat use of breeding Swamp Francolin relative to availability at Koshi Tappu differed significantly between seasons $\left(\Lambda=0.366, F_{6,26}=2.83, P=0.03\right)$. Habitat use relative to availability by Swamp Francolin was ranked as Woodland-Grassland $>$ Wet Grassland $>$ Woodland $>$ Dry Grassland during the breeding season, Woodland-Grassland $>$ Wet Grassland $>$ Dry Grassland $>$ Woodland during the summer and Dry Grassland $>$ Woodland $>$ WoodlandGrassland $>$ Wet Grassland during the Monsoon (Table 2).

\section{Human impacts}

The number of people recorded using the study site at Koshi Tappu reserve did not vary significantly with time of day $\left(F_{1,30}=1.54, P=0.225\right)$ or season $\left(F_{2,30}=1.40, P=0.261\right)$. On average, 6.75 ( \pm o.64) people (range $0-30$ individuals) were present in each section of the study area during the early and late morning. Overall, an average of 40.4 ( \pm 15.6) people (range 17-71) were recorded within the area of the reserve covered by the bird surveys, with over 1oo people being present within the eastern section of the reserve. There was a significant relationship between the number of Swamp Francolin and the number of people recorded early in the morning during all seasons $(P<0.001$; Figure 2). However, the strength of the relationship was not the same across all seasons $\left(F_{2,48}=3.50, P=0.038\right)$, although the general trend for a higher number of birds to be present in areas were the number of people was lower, was the same (Figure 2).

The number of livestock recorded in the study site at Koshi Tappu varied significantly with time of day $\left(F_{1,30}=7.64, P=0.010\right)$, but not with season $\left(F_{2,30}=2.13, P=0.136\right)$. More livestock were recorded later in the morning compared with early in the morning during all seasons, but especially during the breeding season. On average, $5.27( \pm 0.54)$ livestock (range o-20) were recorded in the early morning and 9.07 ( \pm 0.97) livestock (range o-29) in the late morning. Overall, an average of 31.6 ( \pm 16.7) livestock (range 0-51) was recorded within the area of the reserve covered by the bird surveys in the early morning and 54.4 ( \pm 16.9 ) livestock (range 34-87) in the late morning. Throughout the eastern section of the reserve over 120 
Table 2. Ranking matrix for Swamp Francolin at Koshi Tappu, Nepal based on early morning point counts. The positive sign indicates that the row habitat was used more than the column habitat, relative to availability, and the minus sign means the opposite.

\begin{tabular}{|c|c|c|c|c|c|}
\hline & Woodland & Wood-Grass & Wet Grassland & Dry Grassland & Rank \\
\hline \multicolumn{6}{|c|}{ (a) Breeding season } \\
\hline Woodland & & - & - & + & 1 \\
\hline Grass/Wood & +++ & & + & +++ & 3 \\
\hline Wet Grassland & + & - & & +++ & 2 \\
\hline Dry Grassland & - & - & - & & $\mathrm{o}$ \\
\hline \multicolumn{6}{|c|}{ (b) Summer season } \\
\hline Woodland & & - & - & - & $\mathrm{o}$ \\
\hline Grass/Wood & +++ & & + & + & 3 \\
\hline Wet Grassland & +++ & - & & + & 2 \\
\hline Dry Grassland & + & - & - & & 1 \\
\hline \multicolumn{6}{|c|}{ (c) Monsoon season } \\
\hline Woodland & & + & + & - & 2 \\
\hline Grass/Wood & - & & +++ & - & 1 \\
\hline Wet Grassland & - & - & & - & $\mathrm{o}$ \\
\hline Dry Grassland & + & + & +++ & & 3 \\
\hline
\end{tabular}

livestock were regularly present each day. The general relationship between the number of Swamp Francolin and number of livestock was the same in all seasons $\left(F_{2,48}=0.421, P=0.628\right.$; Figure 2), but was not significant (all $P>0.05$ ).

\section{Discussion}

The most appropriate field protocol, time and season for determining abundance

The number of calling birds recorded varied with respect to field protocol, season and time of day. As expected, the highest number of calling birds was recorded during February and March, the period we classified as the breeding season, with lower numbers of calling birds being recorded in summer (April-May) and monsoon (June-July) periods. These differences are assumed to be due to breeding activity of the birds and climatic conditions; during the breeding season males call most actively to defend territories or attract females.

In Galliformes, once breeding commences males call less intensively as they are involved with other activities, such as caring for chicks, particularly during the summer period. The cessation of calling during the monsoon may be due to the continuous rainfall and increases in water level which submerges large areas under water and may cause birds to redistribute and stop defending territories. In common with many bird species, particularly those in hot and tropical climates, Swamp Francolin call more intensively early in the morning than later in the day, probably in relation to temperature, but also possibly in response to disturbance (see later). Based on the information presented here the most appropriate method for surveying Swamp Francolin, certainly at Koshi Tappu and based on calling (territorial) male birds, is point counts, undertaken during the breeding season (February-March) and early in the morning (o5h45- o7h15).

\section{Abundance estimation}

The estimated abundance of $15.5-17.7$ birds $\mathrm{km}^{-2}$ at Koshi Tappu is largely comparable with Shakya et al. (2001) who estimated the francolin's abundance at Koshi Tappu as $14.6 \mathrm{~km}^{-2}$. These 

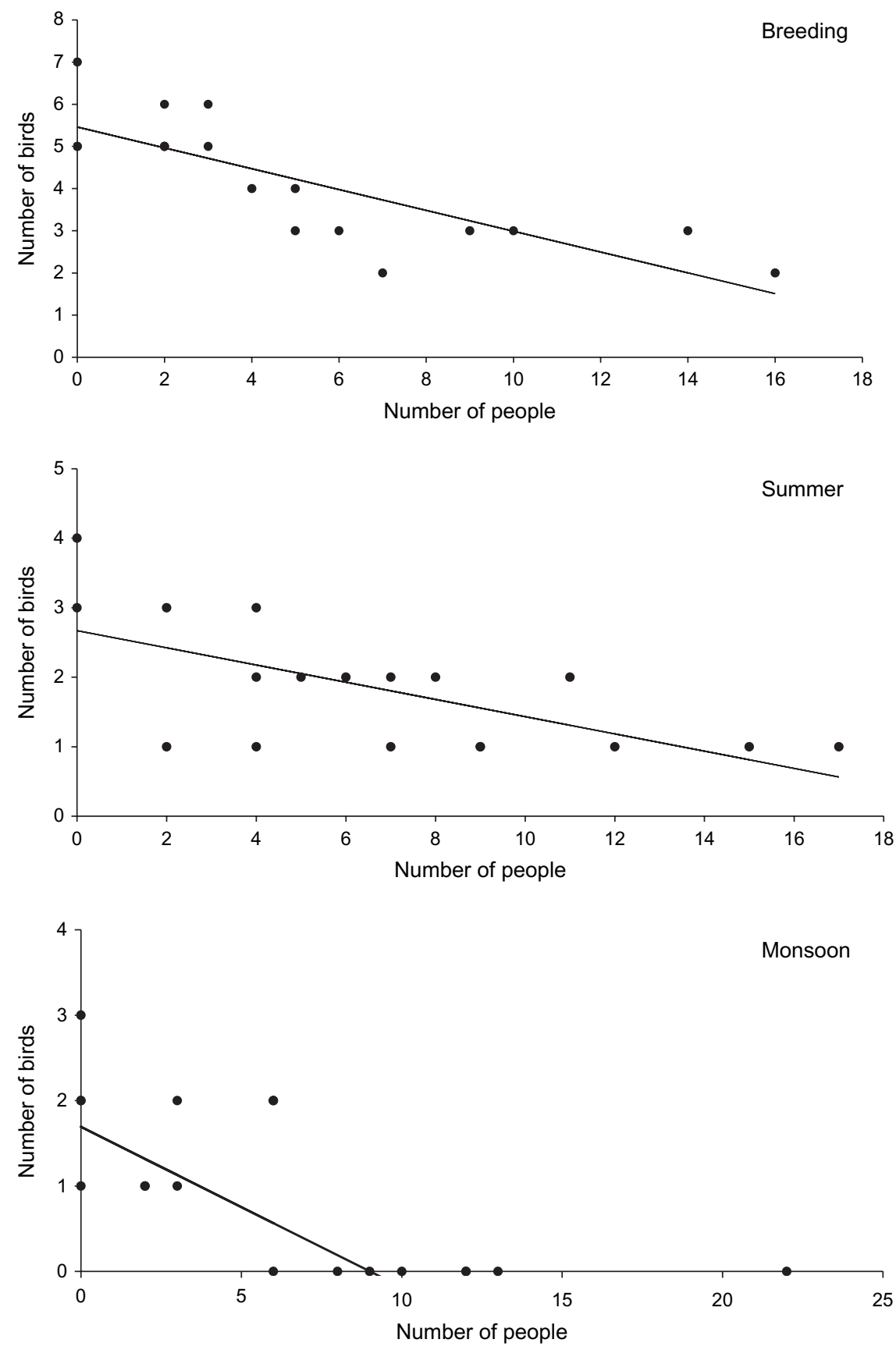

Figure 2. Relationship between the number of people and number of birds recorded by point counts, early in the morning at Koshi Tappu Wildlife Reserve in 2004, during the three seasons. 
authors state that their survey was undertaken in March and April, months which fall into two different periods in this analysis. They also do not provide an assessment of detection distances. They did, however, use a strip width of $300 \mathrm{~m}$, which is both further than the effective detection radius calculated here and usually further than the distance from the eastern embankment, along which transects were walked, to the Koshi River. This means that the estimate produced by Shakya et al. 2001 is likely to be an underestimate of density, or at least a less precise one.

This provides quantitative support for the unsubstantiated assertion that Koshi Tappu Wildlife Reserve is one of the most important areas for the Swamp Francolin and has been so for at least a decade (Inskipp and Inskipp 1991, Shrestha 1992, Baral 1998, Lama 1999, Dahal 2001). Baral (1998) and Shakya et al. (2001) reported that the majority of Swamp Francolin are located within the protected areas in Nepal.

\section{Habitat use}

The Woodland-Grassland mixed habitat appears to be most important for Swamp Francolin, followed by Wet Grassland particularly during the breeding and summer seasons. During the monsoon season, when much of Koshi Tappu is flooded, the areas classified as Dry Grassland are the most favoured and thus are crucial for the species' year-round survival.

\section{Human impacts}

Koshi Tappu is one of the most disturbed protected areas in Nepal, owing to its open boundary and the surrounding habitation of 12 densely populated Village Development Committee areas. As a result many people and livestock utilise the area. People living near Koshi Tappu depend on the forest resources of the reserve for their daily requirements. Collection of fuel wood, regular livestock grazing, logging and collection of other forest products is undertaken daily. Sah (1997) recorded that a total of 1.4 tonnes of fuel wood per household per year is extracted from Koshi Tappu, with extraction of forest products occurring predominantly in the west of the reserve (70.4\%) compared with the east $(29.6 \%)$.

Throughout the study, over 100 people collecting resources from the reserve were counted daily and the presence of people appears to have a negative impact on Swamp Francolin. In areas where people were highest, Swamp Francolin were lowest. This may be due to direct disturbance and habitat alteration through human activities, causing the birds to redistribute or relocate due to reduced suitable habitat availability, but also because the areas that humans cannot easily access (those being wet and with dense vegetation) may actually be those preferred by Swamp Francolin. Livestock grazing in the reserve is prohibited, but it has been a common practice for centuries with many large livestock herders keeping their herds permanently inside the reserve (Sah 1997). During the study period, an average 112 cattle per day entered the reserve across the eastern border, while in the western sector there were many herds of cattle comprising more than one hundred individuals. Although there does not appear to be a direct response from the Swamp Francolin in relation to the presence of livestock, the associated damage to habitat and disturbance arising from people looking after the livestock, for example tree cutting for fuel wood collection or grazing, is likely to be having some impact on Swamp Francolin numbers. Hunting is common in Nepal and although nets and traps suitable for catching birds were regularly encountered in the reserve, no Swamp Francolin hunting was recorded.

\section{Conservation management recommendations}

The results presented here suggest that as long as the pattern of disturbance does not change for the worse (i.e. increase in scale or distribution) then the species may well be able to survive at this site. However, its status is bound to be precarious to some degree as it depends on two habitats 
being in good condition (Wet Grassland for breeding and then higher land in the Dry Grassland to survive the monsoon flooding). So it seems likely that any reduction of extent or quality of either of these will have a negative impact on the population. Furthermore, as stated in the introduction, the perpendicular bunds are repaired each winter, so the survival of the grassland along the eastern embankment is entirely dependent upon this happening every year without fail. Two or three years without these bunds being repaired would result in this habitat disappearing and, with it, the francolin. Whilst there is no reason to suspect that this annual repair work will stop, the consequences for the species may be disastrous if it does.

As noted above an invasive vine Mikania micrantha covers part of the eastern bank of the Koshi River. This native of Central and South America is known as Mile-a-minute Weed and has been considered one of the 100 'World's Worst' invaders (Global Species Invasive Database 2006). It is important to establish if this species poses a threat to the francolin. In addition, it is crucial to assess the species' reproductive output in Koshi Tappu.

\section{Acknowledgements}

The study was funded by the People's Trust for Endangered Species, Chicago Board of Trade/ Chicago Zoological Society and the Wildlife Conservation Society's Research fellowship Programme. We thank the Department of National Parks and Wildlife Conservation for permission to work in Koshi Tappu Wildlife Reserve and Dr Nicholas Aebischer for statistical advice. Drs Werner Dörgeloh \& Stuart Marsden gave advice that improved the paper.

\section{References}

Aebischer, N. J., Robertson, P. A. and Kenward, R. E. (1993) Compositional analysis of habitat use from animal radio-tracking data. Ecology 74: 1313-1325.

Aitchison, J. (1986) The statistical analysis of compositional data. New York: Chapman \& Hall.

Ali, S. and Ripley, S. D. (1987) Handbook of the birds of India and Pakistan. Compact Edition. Delhi: Oxford University Press.

Baral, H. S. (1998) Status, distribution and habitat preferences of swamp francolin in Nepal. - Ibisbill 1: 35-59.

Baral, H. S. and Inskipp, C. (2005) Important Bird Areas in Nepal: key sites for conservation. Kathmandu, Nepal and Cambridge, UK: Bird Conservation Nepal and BirdLife International.

BirdLife International (2004) Francolinus gularis. In: IUCN 2007. 2007 IUCN Red List of Threatened Species. www.iucnredlist. org. Downloaded on 02 January 2008

Buckland, S. T., Anderson, D. R., Burnhan, K. P., Laake, J. L., Borchers, D. I., and Thomas, L. (2001) Introduction to distance sampling. Oxford, UK: Oxford University Press.
Dahal, B. R. (2001) Status and conservation of swamp francolin Francolinus gularis in Koshi Tappu Wildlife Reserve, Nepal. A preliminary report. Pp. $134-137$ in M. I. A. Woodburn, P. J. K. McGowan, J. P. Carroll, A. H. Musavi and Z. W. Zhang, eds. Galliformes 2000. Kathmandu, Nepal and Reading, UK: King Mahendra Trust for Nature Conservation and World Pheasant Association.

Fuller, R. A., Carroll, J. P. and McGowan, P. J. K. (2000) Partridges, quails, francolin, snowcocks, guineafowl, and turkeys: status survey and conservation action plans. Gland, Switzerland and Cambridge, UK: IUCN.

Global Species Invasive Database (2006) Mikania micrantha http://www.issg.org/data base.Downloaded on 14 June 2007.

Grimmett, R., Inskipp, C. and Inskipp, T. (200o) Birds of Nepal. Christopher Helm, London.

Inskipp, C. and Inskipp, T. P. (1991) A guide to the birds of Nepal. Second edition. London: Christopher Helm.

Iqubal, P., McGowan, P. J. K., Carroll, J. P. and Rahmani, A. R. (2003) Home range size, habitat use and nesting success of the swamp francolin Francolinus gularis on 
agricultural land in northern India. Bird Conserv. Internatn. 13: 127-138.

IUCN (2006) 2006 IUCN Red List of threatened species. www.iucnredlist.org. Downloaded on 14 June 2007.

Javed, S. and Rahamani, A. R. (1991) Swamp francolin in the north Indian terai. World Pheasant Ass. News 34: 15-18.

Javed, S., Qureshi, Q. and Rahmani, A. R. (1999) Conservation status and distribution of swamp francolin in India. J. Bombay Nat. Hist. Soc. 96: 16-23.

Kalsi, R., Shakya, S., Shrestha, A. K., Javed, S., Baral, H. S., Kaul, R., McGowan, P. J. K. and Carroll, J. P. (2001) Conservation review of the swamp francolin in India and.Nepal. Pp. $242-247$ in M. I. A. Woodburn, P. J. K. McGowan, J. P. Carroll, A. H. Musavi and Z. W. Zhang, eds. Galliformes 200o. Kathmandu, Nepal and Reading, UK: King Mahendra Trust for Nature Conservation and World Pheasant Association.

Kaul, R. and Kalsi, R. S. (1990) Swamp partridge - a pilot survey. World Pheasant Ass. News 30: 3-5.

Lama, S. (1999) Newsletter Nepal Bird Watching Club 1: 3-4.

McGowan, P. J. K., Dowell, S. D., Caroll, J. P. and Aebischer, N. J. (1995) Partridges, quails, francolins, snowcocks and guinea- fowl: status survey and conservation action plan 1995-1999. Gland, Switzerland and Cambridge, UK: IUCN.

McGowan, P. J. K., Javed, S. and Rahmani, A. R. (1996) Swamp francolin Francolinus gularis survey technique: a case study from northern India. Forktail 11: 101-110.

Sarkar, M. S. U. and Sarkar, N. J. (2001) Status, distribution and conservation of Galliformes in Bangladesh. Pp. 32-38 in M. I. A. Woodburn, P. J. K. McGowan, J. P. Carroll, A. H. Musavi and Z. W. Zhang, eds. Galliformes 2000. Kathmandu, Nepal and Reading, UK: King Mahendra Trust for Nature Conservation and World Pheasant Association.

Sah, J. P. (1997) Koshi Tappu wetlands: Nepal's Ramsar site. Bangkok, Thailand: IUCN.

Shrestha, T. K. (1992) Conservation status of swamp partridge Francolinus gularis in Nepal. Gibier Faune Sauvage 9: 553-559.

Shakya, S., Shrestha, A. K., Kalsi, R. S. (2001)

Distribution of the swamp francolin in the terai grasslands of Nepal. Pp. 126-133 in M. I. A. Woodburn, P. J. K. McGowan, J. P. Carroll, A. H. Musavi and Z. W. Zhang, eds. Galliformes 2000. Kathmandu, Nepal and Reading, UK: King Mahendra Trust for Nature Conservation and World Pheasant Association.

\section{BHAGAWAN RAJ DAHAL}

Bird Conservation Nepal, Lazimpat, Kathmandu, Nepal.

\section{PHILIP J. K. McGOWAN*}

Newcastle University Biology Field Station, Close House Estate, Heddom-on-the-wall, Newcastle-upon-Tyre, NE15 OHT, U.K.

\section{STEPHEN J. BROWNE†}

The Game Conservancy Trust, Fordingbridge, Hampshire, SP6 IEF, U.K.

*Author for correspondence; e-mail: director@pheasant.org.uk

†Present address: Fauna \& Flora International, 4th Floor-Jupiter House, Station Road, Cambridge, CB1 2JD, U.K. 